\title{
2. The Local Dimension of Social Innovation
}


